Revista Brasileira de Odontologia Legal - RBOL

\author{
Odontologia Legal
}

\title{
RESPONSABILIDADE ÉTICA E LEGAL DOS PROFISSIONAIS DE SAÚDE QUE INTEGRAM A ESF E NASF DIANTE DE CASOS DE VIOLÊNCIA
}

\section{Ethical and legal responsibility of health professionals participating in the ESF and NASF to cases of violence}

Mona Lisa Cordeiro Asselta da SILVA*, André Henrique do Vale de ALMEIDA**, Juliana de Oliveira MUSSE ${ }^{* * *}$, Jeidson Antônio Morais MARQUES****, Jamilly

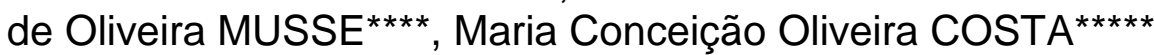

\footnotetext{
*Acadêmica do curso de Odontologia da Universidade Estadual de Feira de Santana e Aluna de Iniciação Científica do Núcleo de Estudos e Pesquisas na Infância e Adolescência NNEPA/UEFS.

** Enfermeiro e Pesquisador do Núcleo de Estudos e Pesquisas na Infância e Adolescência NNEPA/UEFS.

*** Enfermeira pela UCSAL - Bahia.

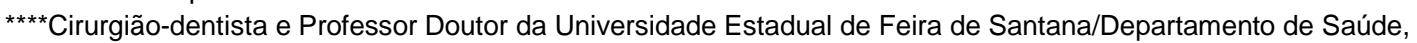
Pesquisador do Núcleo de Estudos e Pesquisas na Infância e Adolescência NNEPA/UEFS.

***** Médica e Professora Doutora da Universidade Estadual de Feira de Santana/Departamento de Saúde, Coordenadora do Núcleo de Estudos e Pesquisas na Infância e Adolescência NNEPA/UEFS.
}

Informação sobre artigo

Recebido: 10 Out 2011

Recebido corrigido: 06 Jun 2012

Aceito em: 17 ago 2012

\section{Autor para correspondência}

Mona Lisa Cordeiro Asselta da Silva

R. Barcelona, 136, Pq. Getúlio Vargas, Res. Arthur A.

Cordeiro, Feira de Santana - BA

mona.cordeiro@hotmail.com

\section{RESUMO}

A violência é um problema de saúde pública em todo mundo de causas múltiplas e que atinge a sociedade de uma maneira ampla. A notificação e denúncia dos casos de violência é uma ferramenta essencial que ajuda a dimensionar essa realidade e a direcionar os investimentos públicos para o seu enfrentamento. O objetivo do estudo foi apresentar o panorama atual da violência contra crianças, adolescentes, mulheres e idosos, além de verificar a responsabilidade ética e legal dos profissionais que integram a ESF e o NASF diante de casos suspeitos ou confirmação de violência. Foram analisados os códigos de ética de dez profissões de saúde, e que na sua atividade laboral entram ou podem entrar em contato com crianças, adolescentes, mulheres e idosos, vitimas da violência. Concluiu-se que é dever do profissional de saúde notificar e denunciar os casos de violência que tenha conhecimento, embora a grande maioria dos códigos de ética das profissões analisadas nesse estudo não traga a palavra violência.

\section{PALAVRAS-CHAVE}

Notificação, violência, Código de Ética, Legislação 


\section{INTRODUÇÃO}

A violência já é entendida como problema de saúde pública em todo mundo ${ }^{1}$, de causas múltiplas e complexas ${ }^{2}$. Crianças, adolescentes, mulheres e idosos são os grupos mais expostos e vulneráveis a sofrerem violações dos seus direitos, afetando direita e indiretamente sua saúde física, mental e emocional ${ }^{3}$.

Silêncio e invisibilidade são palavras que descrevem bem esse fenômeno ${ }^{4}$, que não escolhe raça e/ou classe social'2. Experimentar situações de violência, especialmente quando esta é de natureza doméstica, tem se mostrado comum em toda sociedade. Ocorrem no ambiente familiar e tem como principais agressores pessoas da família ou muito próximas a ela ${ }^{2,5}$.

Crianças e adolescentes são vítimas desde o seu nascimento e no seu cotidiano, e como consequência de maus-tratos, deixam de ser apenas vítimas passando a ser também agressores $^{6}$, demonstrando a severidade e seriedade deste problema. Logo, existe a necessidade de políticas públicas de prevenção de seus agravos e suas conseqüências $^{7}$ com 0 intuito de quebrar esse ciclo vicioso em que na maioria dos casos são reproduzidos por suas vitimas.

Em 1993 foi realizada a Conferência Nacional sobre Direitos Humanos, onde a violência contra mulher foi reconhecida como um obstáculo ao desenvolvimento, à paz e aos ideais de igualdade entre os seres humanos $^{8}$. No entanto, as agressões contra as mulheres continuam à tona em nossa sociedade, apesar de hoje existirem leis que defendam os seus direitos, observa-se um baixo número de notificação. As vítimas na maioria das vezes têm medo de denunciar a violência sofrida e/ou não "podem", pois dependem financeiramente dos agressores que se apresentam principalmente como cônjuge, namorado, amante ou até mesmo excônjuge ou ex-namorado ${ }^{9}$.

A violência contra o idoso vem tomando dimensões cada vez maiores. Diversos países apresentam hoje um acelerado crescimento de população idosa, mas o imaginário popular ainda conforma uma idéia negativa com relação ao envelhecimento ${ }^{10}$. Os direitos do idoso são garantidos mediante a Constituição Federal, a Política Nacional do Idoso e o Estatuto do Idoso, entretanto, a literatura traz as frequêntes $e$ 
Responsabilidade ética e legal dos profissionais de saúde que integram a ESF

diversas formas de violências voltadas para essa parcela da população $^{10}$.

A rede de atenção básica e logo os profissionais de saúde que a integram, compõe um ambiente essencial na prevenção e notificação dos casos de suspeitas ou confirmação da violência, visto que se configura como a porta de entrada do Sistema Único de Saúde (SUS). Iniciada em 1994, a estratégia de Saúde da Família é um projeto dinamizador do SUS, que visa reorientar o modelo de assistência, operacionalizada mediante a implantação de equipes multiprofissionais em unidades básicas de saúde. As equipes são responsáveis pelo acompanhamento de um número definido de famílias, delimitadas geograficamente ${ }^{11}$.

O Ministério da Saúde criou o Núcleo de Apoio à Saúde da Família - NASF, com a Portaria GM no 154, de 24 de Janeiro de 2008, Republicada em 04 de Março de 2008, com o objetivo de apoiar a inserção da Estratégia Saúde da Família na rede de serviços e ampliar a abrangência das ações da Atenção Primaria bem como sua resolutividade ${ }^{12}$.

A Portaria n. 1968/GM, de 25 de outubro de 2001, sinaliza que é dever dos responsáveis técnicos de todas as entidades de saúde integrantes ou participantes, a qualquer título, do Sistema Único de Saúde - SUS, notificar todo caso de suspeita ou confirmação de maustratos contra crianças e adolescentes por elas atendidos, aos Conselhos Tutelares da localidade ${ }^{13}$.

Esses profissionais entram ou podem entrar em contato com as vítimas em sua atividade laboral, pois muitas delas procuram de imediato os sistemas de saúde para o tratamento das consequências de agressões e/ou vão para uma consulta de rotina, e estando o profissional devidamente preparado, sinais de maus-tratos pelo corpo não passarão despercebidos.

O objetivo desse estudo foi apresentar o panorama atual da violência contra crianças, adolescentes, mulheres e idosos, além de verificar a responsabilidade ética e legal dos profissionais que integram a ESF e o NASF diante de casos suspeitos ou confirmação de violência.

\section{MATERIAL E MÉTODO}

Foram analisados os códigos de ética de dez profissões de saúde, que na sua atividade laboral entram ou podem entrar em contato com crianças, adolescentes, mulheres e 
idosos, vitimas da violência, assim como foi estudada a Legislação em vigor relacionada à temática.

As profissões que fizeram parte do estudo são as que compõem a Equipe de Saúde da Família - ESF (Medicina, Enfermagem e Odontologia) e as que estão incluídas no Núcleo de Apoio à Saúde de Família - NASF (Psicologia, Serviço Social, Farmácia, Fisioterapia, Educação Física, Nutrição e Fonoaudióloga). Verificou-se quais artigos dos respectivos documentos estavam relacionados ao tema em questão e a partir daí procedeu-se à sua análise.

\section{RESULTADOS}

\section{Legislação}

A violência é um problema multicausal e o combate à mesma é papel de toda a sociedade, no entanto, cabe ao poder público a formulação e aplicação de leis que previnam e combatam este tipo de agravo. O Decreto-lei 3.688 de 1941, que trata das contravenções penais, no seu artigo 66, traz que 0 profissional de saúde que deixar de comunicar à autoridade competente, crime do qual teve conhecimento no exercício da sua profissão, está infligindo à lei e sofrerá pena de multa $^{14}$. Destacam-se ainda o
Estatuto da Criança e do Adolescente, o Estatuto do Idoso, e a Lei Maria da Penha.

\section{Crianças e adolescentes}

Criado em 13 de julho de 1990, - Estatuto da criança e do Adolescente tem 0 intuito de assegurar os direitos fundamentais da pessoa humana e determinar o dever da família, sociedade e do poder público de garantir com prioridade a efetivação dos direitos referentes à vida, saúde, alimentação, educação, esporte, lazer, profissionalização, cultura, dignidade, respeito, liberdade e convivência familiar e comunitária ${ }^{15}$.

Com relação aos maus-tratos, o artigo $5^{\circ}$ traz que "nenhuma criança ou adolescente será objeto de qualquer forma de negligência, discriminação, exploração, violência, crueldade e opressão, punido na forma da lei qualquer atentado, por ação ou omissão, aos seus direitos fundamentais" ${ }^{\prime 15}$.

Em seu artigo 245 determina que 0 médico, professor ou responsável por estabelecimento de atenção à saúde e de ensino, que deixar de comunicar à autoridade competente os casos de que tenha conhecimento, envolvendo suspeita ou confirmação de maus-tratos contra criança ou adolescente sofrerá 
pena - multa de três a vinte salários de referência, aplicando -se o dobro em caso de reincidência ${ }^{15}$.

\section{Mulheres}

Criada para coibir a violência doméstica e familiar contra a mulher, a Lei no. 11.340 (Maria da Penha), de 07 de agosto de 2006, significou um avanço no combate à violência. As mulheres passaram a dispor de um instrumento legal e o Estado a enxergar a violência contra a mulher.

Entre outras, esta lei traz algumas inovações, como por exemplo, determina que ficam proibidas as penas pecuniárias (pagamento de multas ou cestas básicas); altera o Código de Processo Penal para possibilitar ao juiz a decretação da prisão preventiva quando houver riscos à integridade física ou psicológica da mulher; e permite a autoridade policial prender 0 agressor em flagrante sempre que houver qualquer das formas de violência doméstica contra a mulher ${ }^{16}$.

Criado pela Secretaria Especial de Políticas para as Mulheres em 2005, a Central de Atendimento à Mulher é um serviço do governo federal que auxilia e orienta as mulheres vítimas de violência através do número de utilidade pública $180^{16}$. No sentido de estabelecer a notificação compulsória, no território nacional, do caso de violência contra a mulher que for atendida em serviços de saúde públicos ou privados, foi criada a Lei no. 10.778, de 24 de novembro de 2003. Em seu Art. 5ำ, traz que a inobservância das obrigações estabelecidas nesta Lei constitui infração da legislação referente à saúde pública, sem prejuízo das sanções penais cabíveis $^{17}$.

\section{Idosos}

Com o avançar da idade, a fragilidade adquirida e as nuances características dessa fase da vida, os idosos acabam tornando-se mais vulneráveis. No sentido de regular os direitos assegurados às pessoas com idade igual ou superior a 60 (sessenta) anos, foi criado em 01 de outubro de 2003, a Lei 10.741, que dispõe sobre o Estatuto do Idoso.

O Estatuto do Idoso, em seu artigo 19, afirma que os casos de suspeita ou confirmação de maustratos contra idoso serão obrigatoriamente comunicados pelos profissionais de saúde, à autoridade policial, ao Ministério Público ou ao Conselho do Idoso (Municipal, Estadual e Nacional) ${ }^{18}$.

Para adequar o Estatuto do Idoso, estabelecendo a notificação compulsória dos atos de violência 
praticados contra o idoso atendido em serviço de saúde público ou privado, foi sancionada Lei ํㅜ 12.461 , de 26 de julho de $2011^{19}$.

Em seu art. 2o, traz que 0 art. 19 do Estatuto do Idoso ,passa a vigorar com a seguinte redação: "Os casos de suspeita ou confirmação de violência praticada contra idosos serão objeto de notificação compulsória pelos serviços de saúde públicos e privados à autoridade sanitária, bem como serão obrigatoriamente comunicados por eles". Para os efeitos desta lei, considera-se violência contra o idoso qualquer ação ou omissão praticada em local público ou privado que the cause morte, dano ou sofrimento físico ou psicológico ${ }^{19}$.

\section{Códigos de Ética}

Código de Ética de Medicina

O código de Ética de Medicina traz que é vedado aos inscritos no seu art. $1^{0}$ "Causar dano ao paciente, por ação ou omissão, caracterizável como imperícia, imprudência ou negligência". E no artigo $25^{\circ}$ é vedado ao médico "Deixar de denunciar prática de tortura ou de procedimentos degradantes, desumanos ou cruéis, praticá-las, bem como ser conivente com quem as realize ou fornecer meios, instrumentos, substâncias ou conhecimentos que as facilitem"20. Código de Ética de Enfermagem

O artigo $23^{\circ}$ traz que é dever dos profissionais de enfermagem "encaminhar a pessoa, família e coletividade aos serviços de defesa do cidadão, nos termos da lei". No artigo 34 é vedado ao enfermeiro "provocar, cooperar, ser conivente ou omisso com qualquer forma de violência”21.

Código de Ética de Odontologia

$O$ artigo $4^{\circ}$ traz que constituem dever fundamental dos inscritos "zelar pela saúde e pela dignidade do paciente", assim como "guardar segredo profissional"22.

Código de Ética de Psicologia

artigo $2^{\circ}$ é claro quando traz que é vedado aos profissionais de psicologia praticar ou ser conivente com quaisquer atos que caracterizem negligência, discriminação, exploração, violência, crueldade ou opressão ${ }^{23}$.

Código de Ética de Serviço Social

No artigo $13^{\circ}$ traz que é dever dos profissionais de Serviço Social "denunciar, no exercício da profissão, às entidades de organização da categoria, às autoridades e aos órgãos competentes, casos de violação da Lei e dos Direitos Humanos, quanto a: corrupção, maus tratos, torturas, ausência de 
condições mínimas de sobrevivência, discriminação, preconceito, abuso de autoridade individual e institucional, qualquer forma de agressão ou falta de respeito à integridade física, social e mental do cidadão"24.

Código de Ética de Farmácia

O artigo $15^{\circ}$ do Código de Ética dos profissionais de Farmácia traz que é dever do Farmacêutico "respeitar a vida humana, desde a concepção até a morte, jamais cooperando com atos que intencionalmente atentem contra ela, ou que coloquem em risco sua integridade física ou psíquica” 25.

Código de Ética de Fisioterapia e Terapeuta Ocupacional

O artigo $7^{\circ}$ inciso II traz que é dever os profissionais de Fisioterapia e dos Terapeutas Ocupacionais respeitar a vida humana desde a concepção até a morte, jamais cooperando em ato em que voluntariamente se atente contra ela, ou que coloque em risco a integridade física ou psíquica do ser humano ${ }^{26}$.

Código de Ética de Educação Física

O art. $4^{\circ}$ inciso I traz como princípio "o respeito à vida, à dignidade, à integridade e aos direitos do indivíduo"27.

Código de Ética de Nutrição

É dever do nutricionista descrito no artigo $5^{\circ}$ inciso VII "denunciar às autoridades competentes, inclusive ao Conselho Regional de Nutricionistas, atos de que tenha conhecimento e que sejam prejudiciais à saúde e à vida" ${ }^{28}$.

Código de Ética de Fonoaudiologia

O artigo Art. 6ํinciso II traz que é dever geral dos inscritos "respeitar o cliente e não permitir que este seja desrespeitado"29.

\section{DISCUSSÃO}

Os Códigos de Ética das profissões de Medicina, Enfermagem, Psicologia, Serviço Social e Nutrição trazem a orientação para os profissionais inscritos sobre a notificação e denúncia da violência. É notória a preocupação desses documentos com relação à omissão, ou seja, o pactuar com a situação de violência. É relevante a importância dada por essas categorias profissionais a violência em suas diversas formas, entretanto, tão importante quanto à identificação é a sua denúncia, o que geralmente não ocorre ${ }^{30}$.

No entanto as profissões de Odontologia, Farmácia, Fisioterapia, Educação Física, e Fonoaudiologia não têm um Código de Ética que oriente seus profissionais acerca da notificação e denúncia dos casos de violência, fragilizando este processo, 
já que as leis vigentes em nosso país trazem a obrigatoriedade nesse sentido e muitos destes profissionais não têm conhecimento sobre as mesmas, baseando-se apenas nos seus Códigos de Ética para nortear suas condutas profissionais.

Os Códigos de Ética que não abordam a orientação sobre o tema encontram-se defasados. É necessário constar que 0 dever moral de proteger seu paciente é fundamental para o exercício ético das profissões ${ }^{30}$.

É sabido que a violência se apresenta como um atentado a vida humana e que a não notificação e/ou não denúncia seria uma cooperação destes profissionais para que tal fato aconteça. No entanto, os Códigos de Ética em questão não são claros sobre a violência, precisando incorporar a obrigação desses profissionais em notificar casos em que tenham conhecimento, tratando com maior objetividade esse fenômeno considerado como problema de saúde pública mundial.

\section{CONSIDERAÇÕES FINAIS}

É dever do profissional de saúde notificar e denunciar os casos de violência que tenha conhecimento, em especial os membros da ESF e NASF, visto que a atenção primária é a porta de entrada do Sistema Único de Saúde e existe a probabilidade de detecção dos casos através da atenção continuada à população.

Embora a grande maioria dos códigos de ética não traga claramente a palavra violência, estabelecem o compromisso dos profissionais em denunciar atos prejudiciais à saúde e à vida dos seres humanos. A responsabilidade no combate à violência ultrapassa os muros das unidades de saúde, e deve ser papel de todos. Estado, saúde e sociedade devem caminhar juntos para que se possa vislumbrar uma nova realidade, numa perspectiva de diminuição da violência.

Apenas com uma rede articulada e integrada, capaz de dar - suporte necessário aos profissionais de saúde, a notificação e denúncia dos casos de violência deixarão de ser um tabu, e se tornarão uma realidade, contribuindo decisivamente para a erradicação da violência. 


\section{ABSTRACT}

Violence is a public health problem worldwide with multiple causes and that affects society at large. The notification and reporting of cases of violence is an essential tool that helps scale this reality and to direct public investment to fight them. The study objective was to present the current situation of violence against children, adolescents, women and elderly and also checks the ethical and legal responsibility of professionals within the ESF and NASF before or confirmation of suspected cases of violence. We analyzed the ethics codes of ten health professions, and in their work activity or may come into contact with children, adolescents, women and elderly, victims of violence. It was concluded that it is the duty of the health professional to notify and report cases of violence that has knowledge, although the vast majority of codes of ethics of the professions examined in this study did not bring the word violence.

\section{KEYWORDS}

Reporting, Violence, Ethics, Legislation

\section{REFERÊNCIAS}

1. Costa MCO. Organização Internacional do Trabalho NNEPA/UEFS - Diga Não a Violência Sexual contra Crianças e Adolescentes no seu Município. Brasília: Editora OIT, 2006. v. 1. 52 p.

2. Melani RFH, Dias PEM. Violência doméstica e odontologia. In: Silva M, Zimmermann RD, Paula FJ. Deontologia Ética e Legislação Odontológica. São Paulo: Editora Santos; 2011. p. 267-288.

3. OMS. Organização Mundial da Saúde. Relatório Mundial sobre Violência e Saúde. Genebra. 2002.

4. Minayo MCS. O significado social e para a saúde da violência contra crianças e adolescentes. In M. F. Westphal. Violência e criança. São Paulo: Edusp. 2002.

5. França GV. Medicina legal. 8ª ED. Rio de Janeiro: Guanabara Koogan: 2008. 628p.

6. Minayo MCS. Contextualização da Violência contra crianças e adolescentes. In: Brasil. Ministério da Saúde. Violência faz mal à Saúde. Brasília-DF: Ministério da Saúde. 2004.

7. Neto OC, Moreira MR. A concretização de políticas públicas em direção à prevenção da violência estrutural. Ciência \& Saúde Coletiva, 4(1):33-52, 1999.

8. Silva LL, Coelho EBS, Caponi SNC. Violencia silenciosa: violencia psicológica como condición de la violência física doméstica. Interface - Comunicação, Saúde, Educação, v.11, n.21, p.93-103, jan/abr 2007.

9. Deslandes SF, Gomes F, Silva CMFP. Caracterização dos casos de violência doméstica contra a mulher atendidos em dois hospitais públicos do Rio de Janeiro. Caderno de Saúde Pública, Rio de Janeiro, 16(1):129-137, jan-mar. 2000

10. Fonseca GS, Musse JO, Azevedo ACS, Menezes FS, Silva MLCA. Atuação dos profissionais de saúde na identificação de violências contra idosos. In: Silva RHA. Anais científico do I Encontro de Odontologia Legal de Ribeirão Preto. Ribeirão Preto, 2010. p. 1415.

11. Brasil. Ministério da Saúde. Portaria no 648/GM, de 28 de março de 2006. Brasília: Ministério da Saúde; 2006.

12. Brasil. Ministério da Saúde. Portaria no 154, de 24 de janeiro de 2008. Brasília: Ministério da Saúde; 2008.

13. Brasil. Portaria n. $-1968 / \mathrm{GM}$ de 25 de outubro de $2001\left(^{*}\right)$ PUBLICADA NO DOU № 206 DE 26/10/01 Seção 1 - Página 86.

14. Brasil. Lei $\mathrm{n}^{\circ}$.3.688, de 3 de outubro de 1941. Lei das Contravenções Penais. [lei na Internet, acesso 26 set 2011]. Disponível em:<http://www.planalto.gov.br/CCl VIL_03/Decreto-Lei/Del3688.htm>.

15. Brasil. Lei $\mathrm{n}^{\circ} .8069$, de 13 de julho de 1990. Dispõe sobre o Estatuto 
da Criança e do Adolescente e dá outras providências. [lei na Internet, acesso em 27 set 2011]. Disponível em:<

http://www.planalto.gov.br/ccivil/LEl S/L8069.htm>.

16. Brasil. Lei oㅜ 11.340, de 7 de agosto de 2006. Coíbe a violência doméstica e familiar contra a mulher. [lei na internet, acesso em 27 set 2011]. Disponível em: $<$ http://www.sejus.df.gov.br/sites/40 0/429/00000233.pdf >.

17. Brasil. Lei 10.778, de 24 de novembro de 2003. Estabelece a notificação compulsória, no território nacional, do caso de violência contra a mulher que for atendida em serviços de saúde públicos ou privados. [lei na Internet, acesso em 17 set 2011]. Disponível em: <http://www.planalto.gov.br/CCIVIL/ LEIS/2003/L10.778.htm>.

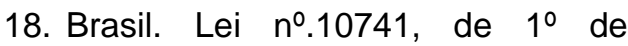
outubro de 2003. Dispõe sobre o Estatuto do Idoso e dá outras providências. [lei na Internet, acesso em 17 set 2011]. Disponível em:

<http://www010.dataprev.gov.br/sisl ex/paginas/42/2003/10741.htm>.

19. Brasil. Lei no 12.461, de 26 de junho de 2011. Estabelece a notificação compulsória dos atos de violência praticados contra o idoso atendido em serviço de saúde. [lei na internet, acesso em 26 set 2011]. Disponível em: <http://www.planalto.gov.br/ccivil_0 3/ Ato20112014/2011/Lei/L12461.htm>.

20. CFM. Conselho Federal de Medicina. Resolução no 1931/2009 de 17 de setembro de 2009. Aprova - Código de Ética Médica [resolução na internet, acesso em 10 de junho de 2011] Disponível em:

<http://www.cremesp.org.br/library/ modulos/legislacao/versao_impress ao.php?id=8822 > .

21. COFEN. Conselho Federal de Enfermagem. Resolução $\mathrm{n}^{\circ}$ $311 / 2007$ de 08 de fevereiro de 2007. Aprova o Código de Ética dos Profissionais de Enfermagem [resolução na internet, acesso em 10 de junho de 2011] Disponível em:

$<$ http://portalcofen.gov.br/sitenovo/n ode/4394>.
22. CFO. Conselho Federal de Odontologia. Resolução no 42/2003 de 20 de maio de 2003. Dispõe sobre 0 Código de ética Odontológica [resolução internet, acesso em 21 de junho de 2011] Disponível em: $<$ http://www.forp.usp.br/restaurador a/etica/c_etica/ceo_05_03.pdf>.

23. CFP. Conselho Federal de Psicologia. Resolução no 010/2005 de 27 de agosto de 2005 Aprova o Código de Ética Profissional do Psicólogo. [resolução internet, acesso em 10 de junho de 2011 ] Disponível em: <http://www.crpsp.org.br/portal/orien tacao/codigo/fr_codigo_etica_new.a spx>.

24. CFESS. Conselho Federal de Serviço Social. Resolução nº 273/1993 de 13 de março de 1993. Institui o Código de Ética Profissional dos Assistentes Sociais. [resolução internet, acesso em 10 de junho de 2011] Disponível em:

<http://www.cfess.org.br/arquivos/C EP2011_CFESS.pdf>.

25. CFF. Conselho Federal de Farmácia. Resolução no 417/2004 de 29 de setembro de 2004. Aprova - Código de Ética da Profissão Farmacêutica [resolução na internet, acesso em 10 de junho de 2011]. Disponível em: <http://www.cff.org.br/pagina.phd?id $=167 \&$ titulo=Código+de+Ética $>$.

26. CONFFITO. Conselho Federal de Fisioterapia. Resolução ํo 10/1978 de 03 de julho de 1978. Dispõe sobre o Código de ética dos Profissionais da Fisioterapia [resolução na internet, acesso em 10 junho de 2011]. Disponível em: <http://www.coffito.org.br/conteudo/ com_view.asp?secao $=26>$.

27. CONFEF. Conselho Federal de Educação Física. Resolução no 056/2003 de 18 de Agosto de 2003. Aprova o Código de Ética dos Profissionais de Educação Física [resolução na internet, acesso em 10 de junho de 2011] Disponível em:

$<$ http://www.confef.org.br/extra/resol ucoes/conteudo.asp?cd_resol=103>

28. CFN. Conselho Federal do Nutricionista. Resolução $n^{\circ}$ 334/2004 de 10 de maio de 2004. Dispõe sobre o Código de Ética do 
Nutricionista [resolução internet, acesso em 10 de junho de 2011] Disponível em: $<$ http.//www.cfn.org.br/novosite/pdf/ codigo/codigo\%20de\%20etica_nova \%20redacao.pdf.>.

29. CFFa. Conselho Federal de Fonoaudiologia. Resolução no 305/2004 de 06 de março de 2004. Dispõe sobre o Código de ética dos Profissionais da Fonoaudiologia [resolução na internet, acesso em 10 de junho de 2011] Disponível em:

<http://www.fonoaudiologia.org.br>.

30. Saliba O, Garbin CAS, Garbin AJI, Dossi AP. Responsabilidade do profissional de saúde sobre a notificação de casos de violência doméstica. Revista de Saúde Pública. 2007;41(3):472-7. 